\title{
Inhibition of Hippocampal $\beta$-Adrenergic Receptors Impairs Retrieval But Not Reconsolidation of Cocaine-Associated Memory and Prevents Subsequent Reinstatement
}

\author{
James M Otis', Michael K Fitzgerald' and Devin Mueller*,', \\ 'Department of Psychology, University of Wisconsin-Milwaukee, Milwaukee, WI, USA
}

\begin{abstract}
Retrieval of drug-associated memories is critical for maintaining addictive behaviors, as presentation of drug-associated cues can elicit drug seeking and relapse. Recently, we and others have demonstrated that $\beta$-adrenergic receptor ( $\beta$-AR) activation is necessary for retrieval using both rat and human memory models. Importantly, blocking retrieval with $\beta$-AR antagonists persistently impairs retrieval and provides protection against subsequent reinstatement. However, the neural locus at which $\beta$-ARs are required for maintaining retrieval and subsequent reinstatement is unclear. Here, we investigated the necessity of dorsal hippocampus (dHipp) $\beta$-ARs for drugassociated memory retrieval. Using a cocaine conditioned place preference (CPP) model, we demonstrate that local dHipp $\beta$-AR blockade before a CPP test prevents CPP expression shortly and long after treatment, indicating that dHipp $\beta$-AR blockade induces a memory retrieval disruption. Furthermore, this retrieval disruption provides long-lasting protection against cocaine-induced reinstatement. The effects of $\beta$-AR blockade were dependent on memory reactivation and were not attributable to reconsolidation disruption as blockade of $\beta$-ARs immediately after a CPP test had little effect on subsequent CPP expression. Thus, cocaine-associated memory retrieval is mediated by $\beta$-AR activity within the dHipp, and disruption of this activity could prevent cue-induced drug seeking and relapse long after treatment.

Neuropsychopharmacology (2014) 39, 303-310; doi:I0.1038/npp.2013.187; published online 28 August 2013
\end{abstract}

Keywords: noradrenergic beta-receptor; norepinephrine; dorsal hippocampus; cocaine-induced reinstatement; drug abuse; reconsolidation

\section{INTRODUCTION}

Drug-associated cues elicit craving and relapse in addicts (Childress et al, 1986; Foltin and Haney, 2000), and disruption of drug-cue associations would therefore limit relapse susceptibility. Recent evidence reveals that memory retrieval is susceptible to disruption that is persistent. Specifically, preventing retrieval with $\beta$-adrenergic receptor $(\beta-A R)$ antagonists causes long-lasting impairments in drug-associated memory retrieval in rats (Otis and Mueller, 2011; Otis et al, 2013) and retrieval of visual, word, and drug-associated memories in humans (Kroes et al, 2010, 2012; Zhao et al, 2010). This retrieval impairment provides protection against cocaine-induced reinstatement (Otis and Mueller, 2011), confirming that disruption of retrieval would limit relapse susceptibility. Despite the requirement of $\beta$-ARs in retrieval and the

\footnotetext{
*Correspondence: Dr D Mueller, Department of Psychology, University of Wisconsin-Milwaukee, 244I East Hartford Avenue, Garland Hall 224, P.O. Box 4I3, Milwaukee, WI 5320I-04I3, USA, Tel: +| 4I4229 6II3, Fax: + 4I4229 5219, E-mail: devinm@uwm.edu Received 19 April 2013; revised 26 July 2013; accepted 31 July 20 I3; accepted article preview online 2 August 2013
}

pivotal role of retrieval in promoting drug seeking, the neural locus in which $\beta$-ARs maintain drug-associated memory retrieval necessary for subsequent reinstatement remains unknown.

Previous work has demonstrated a critical role of the dorsal hippocampus (dHipp) in memory retrieval and context-induced reinstatement. dHipp lesions or inactivation prevent context-dependent fear memory retrieval (Corcoran and Maren, 2001; Kim and Fanselow, 1992). Moreover, norepinephrine (NE) and $\beta$-AR activation within dHipp are critical for contextual fear memory retrieval, but not for fear expression alone (Murchison et al, 2004). The dHipp is activated by drug-associated cue exposure in both rodents (Neisewander et al, 2000; Hearing et al, 2010) and humans (Hermann et al, 2006), and dHipp inactivation prevents context-driven drug seeking and reinstatement (Fuchs et al, 2005; Meyers et al, 2006). Despite evidence that dHipp is involved in memory retrieval and reinstatement, it remains unclear whether dHipp $\beta$-AR activation is required for drug-associated memory retrieval and subsequent druginduced reinstatement.

Here, we determined the necessity of dHipp $\beta$-AR activation for retrieval of a cocaine-associated memory using a conditioned place preference $(\mathrm{CPP})$ procedure, in 
which environmental stimuli are paired with cocaine administration. Following acquisition of a CPP, we examined the effects of dHipp $\beta$-AR blockade on CPP memory retrieval by infusing the $\beta$-AR antagonist nadolol into the dHipp immediately before a CPP test. Next, rats were exposed to daily microinfusion-free CPP tests to determine whether the effects of $\beta$-AR antagonism on CPP retrieval were persistent. We then determined whether the nadololinduced retrieval impairment would provide long-lasting protection against cocaine-induced reinstatement. Finally, we determined whether the effects of nadolol were specific to the hippocampus, due to reconsolidation blockade, or due to effects on behavioral expression unrelated to memory retrieval. Our data reveal that drug-associated memory retrieval is maintained by $\beta$-AR activity within the dHipp, and disruption of this activity induces a persistent retrieval impairment that protects against subsequent reinstatement.

\section{MATERIALS AND METHODS}

\section{Subjects and Surgery}

Male Long-Evans rats weighing 300-325 g were weighed, handled, and maintained as previously described (Otis and Mueller, 2011). Experimental procedures were approved by the Institutional Animal Care and Use Committee at the University of Wisconsin-Milwaukee in accordance with National Institutes of Health guidelines.

Surgeries were performed as previously described (Otis et al, 2013). Briefly, rats were anesthetized and implanted with two guide cannulas aimed at the dHipp (AP, - 3.5; ML, \pm 2.5 ; DV,$-3.2 \mathrm{~mm}$ relative to bregma) or the overlying cortex (AP, $-3.5 ; \mathrm{ML}, \pm 2.5, \mathrm{DV},-1.5 \mathrm{~mm}$ relative to bregma). Rats recovered for 7 days before behavioral experiments. Following all experiments, histological verification of cannula placements was performed using a cresyl violet stain.

\section{Drugs}

Cocaine $\mathrm{HCl}$ was dissolved in sterile $0.9 \%$ saline at a concentration of $10 \mathrm{mg} / \mathrm{ml}$ and administered at a dose of $10 \mathrm{mg} / \mathrm{kg}$ (i.p.). Nadolol, the $\beta$-AR antagonist, was dissolved in chilled $0.9 \%$ saline at a concentration of 1 or $2 \mu \mathrm{g} / \mu \mathrm{l}$, as described previously (Murchison et al, 2004). The $2 \mu \mathrm{g} / \mu \mathrm{l}$ concentration has been shown to optimally abolish retrieval and reconsolidation of memory (Murchison et al, 2004; Otis et al, 2013). Due to the high sensitivity of nadolol to light, the nadolol solution was covered and infused within $2-3 \mathrm{~min}$ of preparation at a volume of $1 \mu \mathrm{l} /$ side and a rate of $0.5 \mu \mathrm{l} / \mathrm{side} / \mathrm{min}$.

\section{Place Preference Apparatus}

Place conditioning and testing were conducted in a threechamber apparatus as previously described (Otis and Mueller, 2011). Briefly, two distinguishable conditioning chambers were separated by a smaller center chamber. During conditioning, rats were isolated within the conditioning chambers. During baseline and post-conditioning CPP tests, rats had access to the entire apparatus. Time was recorded during CPP tests with four infrared photobeams located in the conditioning chambers. Locomotor activity was also recorded by quantifying total photobeam breaks.

\section{Conditioning and Testing}

Baseline preferences were examined by allowing rats to access all three chambers for $15 \mathrm{~min}$. Rats spent equivalent time within the larger conditioning chambers, but less time within the center chamber. ANOVA revealed an effect of chamber for all rats during the baseline test $\left(\mathrm{F}_{2,124}=67.98\right.$, $p<0.001$ ), and post-hoc analyses confirmed that less time was spent within the center chamber than either of the conditioning chambers ( $p$ 's $<0.001)$, whereas equivalent time was spent within the conditioning chambers $(p>0.05)$. Thus, an unbiased procedure was used, in which rats were assigned to receive cocaine in one of the two conditioning chambers in a counterbalanced and pseudorandom manner. Following baseline testing, rats were given four pairings of cocaine in one chamber, and four pairings of saline in another chamber in an alternating manner over 8 days. Two days following conditioning, rats were given daily CPP tests with full access to all the three chambers for 15 min to test for retrieval of the CPP memory. The short CPP tests were chosen to induce reconsolidation while limiting CPP extinction across the initial tests. This length of test is standard for testing reconsolidation of drugassociated memories, and previous investigations using this length of CPP test have revealed a role for dHipp or $\beta$-AR signaling in reconsolidation of CPP memories (eg, Bernardi et al, 2009 and Otis et $a l, 2013$ ) and self-administration memories (eg, Ramirez et al, 2009; Wells et al, 2011 and Wouda et al, 2010). A CPP was determined when rats spent significantly more time within the previously cocainepaired chamber than in the saline-paired chamber.

\section{Experimental Manipulations}

Basic experimental protocols are outlined in Supplementary Table S1. To assess the involvement of dHipp $\beta$-AR activation for CPP memory retrieval, dHipp microinfusions of saline or nadolol were administered $15 \mathrm{~min}$ before the first CPP test or before selective exposure to the previously cocaine-paired chamber. Daily microinfusion-free CPP tests were then given to determine the persistent effects of $\beta$-AR blockade on CPP memory retrieval. Following the third test, rats were given a 14-day break from testing followed by drug-free CPP tests to determine the long-term effects of nadolol treatment. Repeated CPP tests result in extinction of the CPP as no cocaine is administered during those tests. Moreover, cocaine is known to reinstate CPP expression in extinguished rats (Mueller and Stewart, 2000). Thus, we administered a priming injection of saline or cocaine (5 or $10 \mathrm{mg} / \mathrm{kg}$, i.p.) $15 \mathrm{~min}$ before the final CPP test to determine the effects of previous nadolol treatment on cocaineinduced reinstatement.

We next examined whether dHipp $\beta$-AR activation is required for CPP memory reconsolidation. dHipp microinfusions of saline or nadolol were administered immediately after the first CPP test, followed by daily nadolol-free CPP tests. Following these tests, rats were administered cocaine before a test for reinstatement. 
a
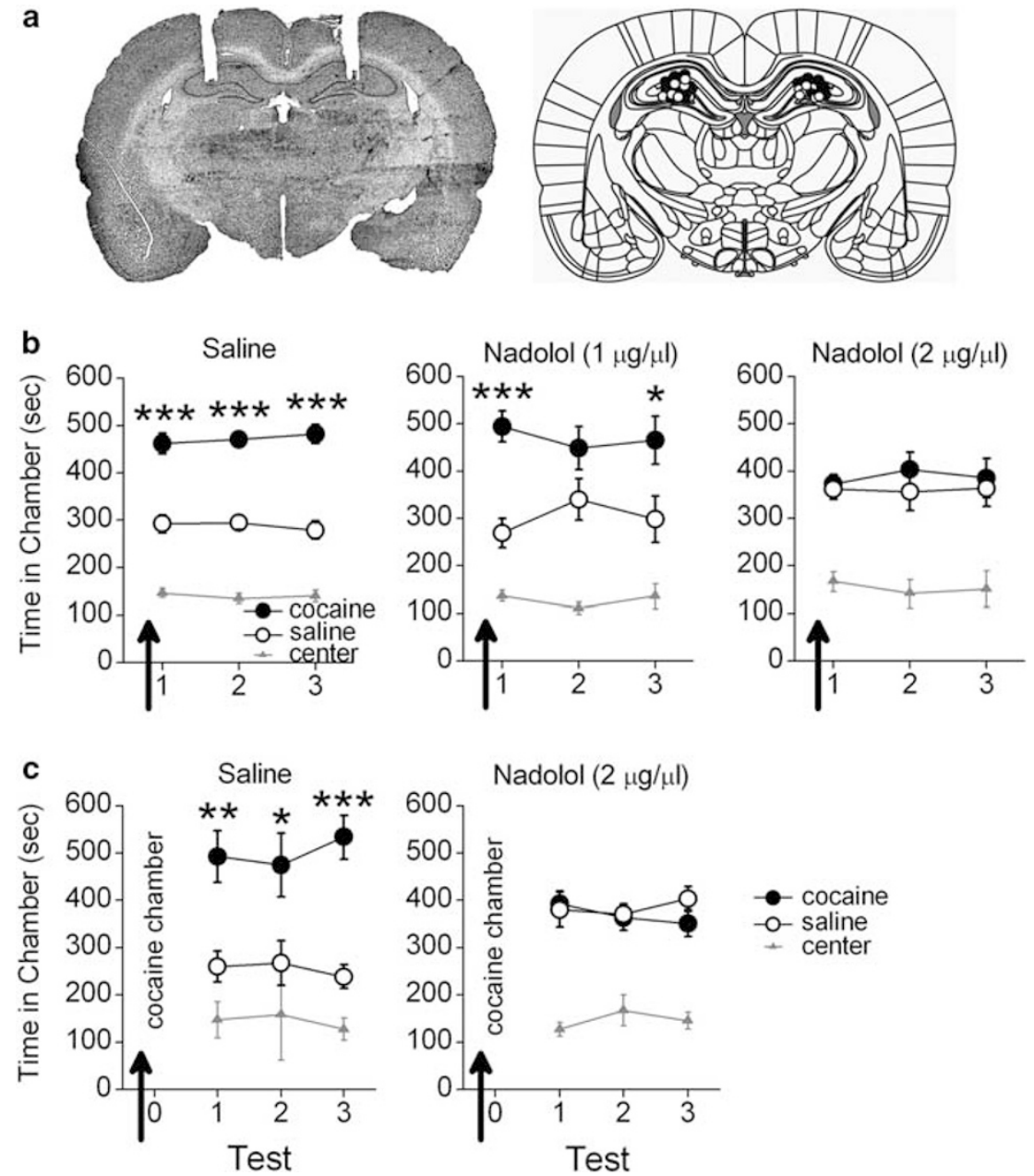

Figure I $\beta$-AR blockade in dHipp disrupts CPP memory retrieval. (a) The photomicrograph shows representative guide cannula tracts. Coronal drawings (bregma, $-3.24 \mathrm{~mm}$ ) show injector tip placements for dHipp microinfusions. (b) dHipp microinfusions (arrows) of a high dose of nadolol ( $n=16$ ), but not a low dose of nadolol $(n=9)$ or saline $(n=17)$, prevented rats from expressing a CPP during that test and subsequent microinfusion-free tests. (c) dHipp microinfusions (arrows) of nadolol $(n=7)$ but not saline $(n=5)$ before confinement to the previously cocaine-paired chamber prevented CPP expression during subsequent microinfusion-free tests. ${ }^{*} p<0.05$, ** $p<0.0$ I; ***** $p<0.00$ l.

We also investigated the possible effects of nadolol on $\mathrm{CPP}$ expression that were independent of memory retrieval or reconsolidation. Saline or nadolol was administered in the absence of testing, which was followed $24 \mathrm{~h}$ later by a drug-free CPP test. Next, we determined whether dHipp nadolol itself induced a CPP or aversion. Following baseline testing, rats were trained to associate one chamber, but not another, with nadolol over 2 days. dHipp microinfusions of saline or nadolol were administered 15 min before each conditioning session. Following conditioning, rats were given a drug-free CPP test. Finally, the effects of dHipp nadolol microinfusions on locomotor activity were measured as photobeam breaks during a CPP test.

\section{Data Analysis}

Data were analyzed by comparing time spent between the cocaine, saline, and center chambers across CPP tests and between groups using repeated measures ANOVA. Following a significant main effect, Tukey's Honestly Significant Difference post-hoc tests were used to compare the amount of time spent within the cocaine-paired versus saline-paired chambers for single or across multiple CPP tests. Locomotor activity was analyzed by comparing the number of photobeam breaks between groups using one-way ANOVA.

\section{RESULTS}

\section{dHipp $\beta$-AR Blockade Induces a Persistent Impairment in Retrieval of a CPP Memory}

We determined the necessity of dHipp $\beta$-AR activation for cocaine-associated CPP memory retrieval. Following conditioning, rats were given daily CPP tests, with bilateral microinfusions of saline $(n=17)$, a low $(1 \mu \mathrm{g} / \mu \mathrm{l} ; n=9)$ or a high dose of nadolol $(2 \mu \mathrm{g} / \mu \mathrm{l} ; n=16)$ before the first test. Rats infused with saline or the low dose of nadolol demonstrated a CPP for the previously cocaine-paired chamber during the first test and subsequent microinfusion-free tests, whereas rats infused with the high dose of nadolol did not (Figure 1b). ANOVA revealed a significant effect of chamber $\left(\mathrm{F}_{2,78}=81.77, p<0.001\right)$ and a chamberby-nadolol dose interaction $\left(\mathrm{F}_{4,78}=3.08, p<0.05\right)$. Post hoc analyses confirmed that rats treated with saline or a low 
dose of nadolol spent significantly more time in the previously cocaine-paired chamber than in the saline-paired chamber during the first CPP test and subsequent CPP tests overall ( $p$ 's $<0.05$ ), whereas rats treated with a high dose of nadolol did not ( $p$ 's $>0.05)$. Thus, a single dHipp microinfusion of nadolol $(2 \mu \mathrm{g} / \mu \mathrm{l})$ induced a persistent impairment in CPP memory retrieval.

We next determined whether dHipp $\beta$-AR blockade before selective exposure to the previously cocaine-paired chamber, but not to the saline-paired chamber, would induce a persistent CPP retrieval impairment. Rats were given dHipp microinfusions of saline $(n=5)$ or nadolol $(2 \mu \mathrm{g} / \mu \mathrm{l} ; n=7)$ before exposure to the cocaine-paired chamber for $15 \mathrm{~min}$, followed by daily microinfusion-free CPP tests. Rats infused with saline demonstrated a CPP during all tests, whereas rats infused with nadolol did not (Figure 1c). ANOVA revealed a significant effect of chamber $\left(\mathrm{F}_{2,20}=29.49, p<0.001\right)$ and a chamber-by-group interaction $\left(\mathrm{F}_{2,40}=5.95, p<0.01\right)$. Post hoc analyses confirmed that rats treated with saline spent significantly more time in the previously cocaine-paired chamber than in the saline-paired chamber during all CPP tests $(p s<0.05)$, whereas rats treated with nadolol did not ( $p s>0.05$ ). Thus, a dHipp microinfusion of nadolol before selective exposure to the cocaine-associated chamber induced a persistent impairment in CPP memory retrieval.

\section{dHipp $\beta$-AR Blockade Provides Lasting Protection Against Cocaine-Induced Reinstatement}

Multiple unreinforced CPP tests result in extinction learning. Following extinction, reinstatement of a CPP can be induced by administration of cocaine (Mueller and Stewart, 2000).
Thus, we examined whether the persistent retrieval impairment caused by dHipp nadolol microinfusions would provide protection against reinstatement. Following conditioning and daily CPP tests with microinfusions of saline or nadolol before the first test only (Figure 1b), rats were given a 14-day break followed by daily CPP tests during which no CPP was expressed. Rats were then tested for cocaine-induced reinstatement, with either a $5 \mathrm{mg} / \mathrm{kg}$ or a $10 \mathrm{mg} / \mathrm{kg}$ dose of cocaine, in the absence of saline or nadolol microinfusions. Rats previously infused with saline or the low dose of nadolol expressed a CPP during the reinstatement test regardless of the dose of cocaine administered, whereas rats previously infused with the high dose of nadolol did not (Figure 2). When comparing each group's final CPP extinction test with the reinstatement test across groups, ANOVA revealed an effect of chamber $\left(\mathrm{F}_{2,68}=47.14, \quad p<0.001\right)$, a chamber-by-test interaction $\left(\mathrm{F}_{2,68}=15.66, p<0.001\right)$, a chamber-by-test-by-nadolol dose interaction $\left(\mathrm{F}_{4,68}=3.10, p<0.05\right)$, but no chamber-by-testby-nadolol dose-by-reinstatement dose interaction $\left(\mathrm{F}_{2,68}=\right.$ $0.60, p>0.05)$. Post hoc analyses confirmed that all groups spent equivalent time within the previously cocaine-paired and saline-paired chambers during the final CPP extinction tests ( $p$ 's $>0.05)$. However, rats previously treated with saline or the low dose of nadolol spent significantly more time within the previously cocaine-paired chamber than in the saline-paired chamber during the cocaine-induced reinstatement test regardless of the dose of cocaine administered ( $p$ 's $<0.05$ ), whereas rats treated with the high dose of nadolol did not ( $p$ 's $>0.05$ ). Thus, only rats treated with saline or the low dose of nadolol expressed a CPP during the reinstatement test. We also confirmed that saline
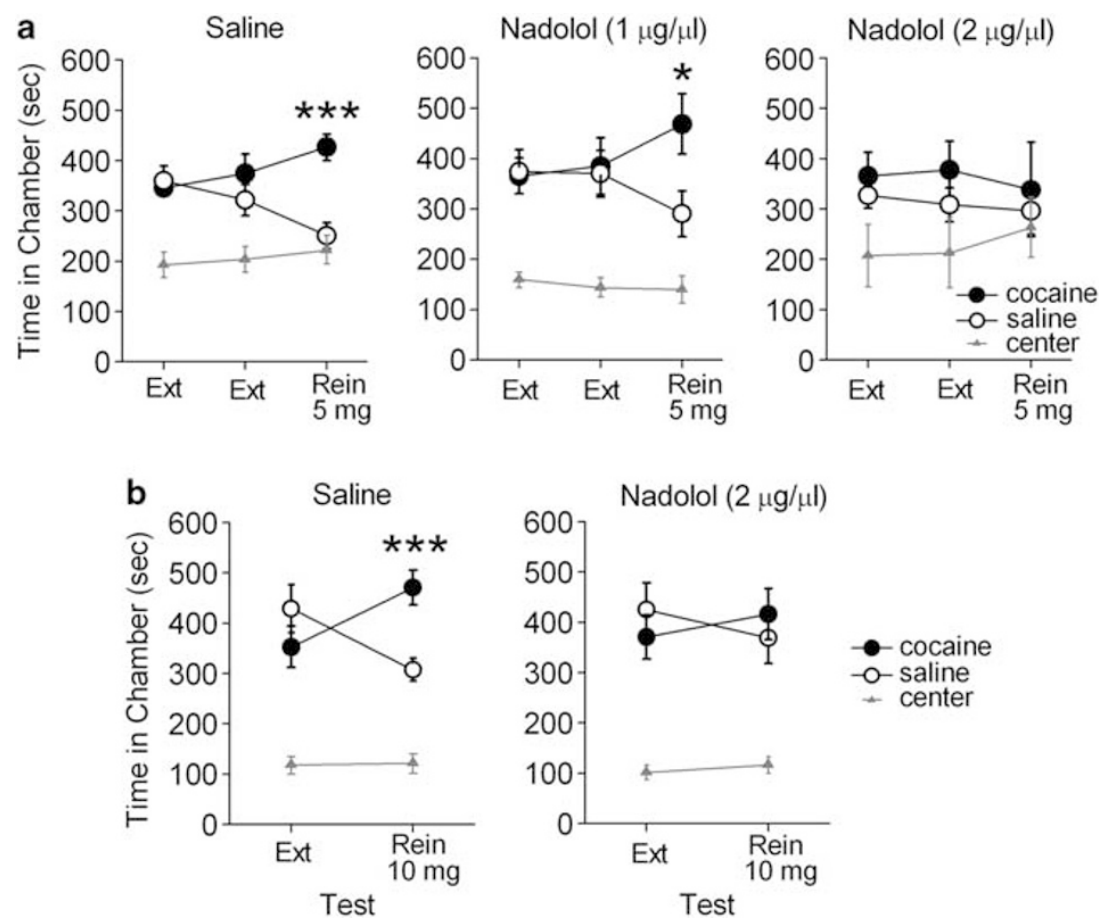

Figure $2 \beta$-AR blockade in dHipp during retrieval provides long-lasting protection against reinstatement to a high dose of cocaine. (a) Rats did not express a CPP during a final CPP extinction test. The following day, rats previously treated with either saline $(n=8)$ or the low dose of nadolol $(n=9)$, but not with the high dose of nadolol $(n=6)$, expressed reinstatement of the CPP following a priming injection of a low dose of cocaine (5 mg/kg). (b) Rats treated with the saline $(n=8)$, but not the high dose of nadolol $(n=9)$, also expressed reinstatement of the CPP following injection of a high dose of cocaine $(10 \mathrm{mg} / \mathrm{kg}) . * * p<0.01$ and $* * * * p<0.001$. Ext, extinction; Rein, Reinstatement. 
did not induce reinstatement of the CPP (Supplementary Figure S1), revealing that injection procedures alone had no effect. Thus, disruption of CPP memory retrieval with dHipp nadolol microinfusions prevented subsequent cocaine-induced reinstatement.
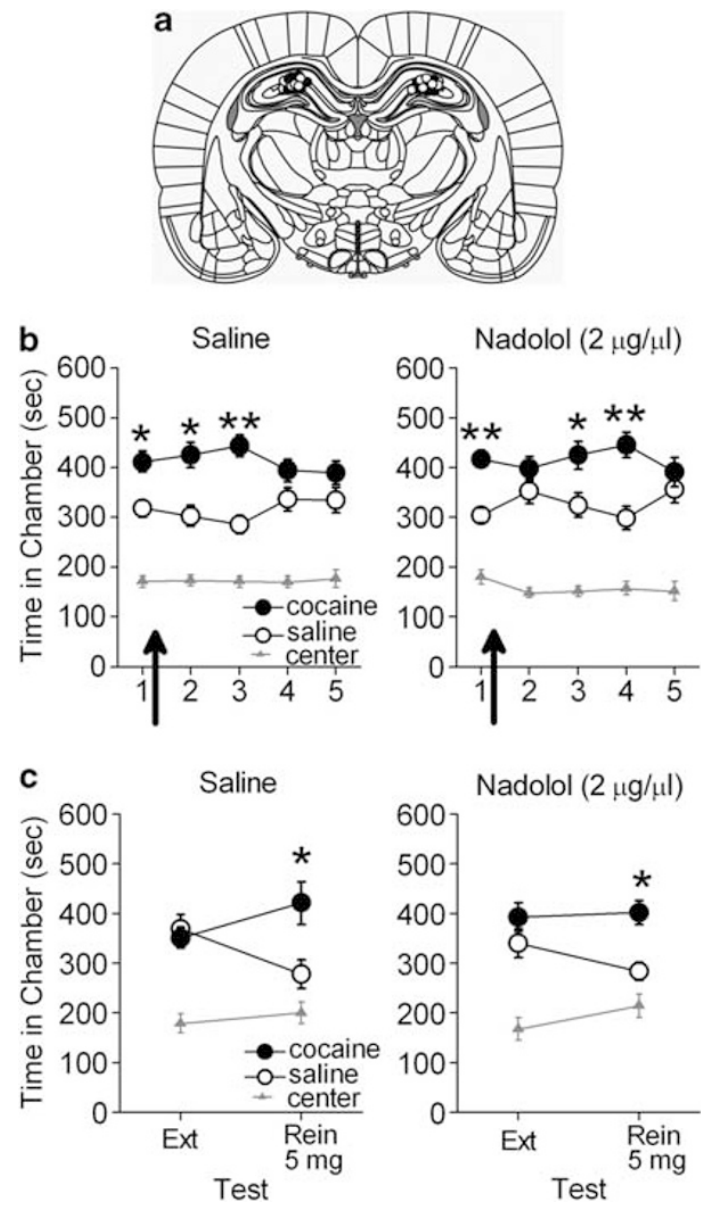

Figure $3 \quad \beta$-AR blockade in dHipp does not prevent CPP memory reconsolidation. (a) Coronal drawings (bregma, $-3.24 \mathrm{~mm}$ ) showing injector tip placements for dHipp microinfusions. (b) dHipp microinfusions (arrows) of nadolol $(n=18)$ or saline $(n=17)$ did not prevent rats from expressing a CPP during subsequent microinfusion-free tests. (c) Rats did not show a CPP during the final extinction test. The following day, previously saline- and nadolol-treated rats expressed cocaine-induced reinstatement of the CPP. ${ }^{*} p<0.05$ and ${ }^{*} * p<0.01$.

\section{dHipp ß-AR Blockade Does Not Impair Reconsolidation of a CPP Memory}

Disruption of dHipp activity impairs reconsolidation of contextual fear (Debiec et al, 2002; Lee et al, 2004) and drug-associated memories (Ramirez et al, 2009). Therefore, reconsolidation blockade could explain the persistent retrieval impairment observed in this study. Thus, we determined the necessity of dHipp $\beta$-AR activation for reconsolidation of a cocaine-associated CPP memory. Following conditioning, rats were given daily CPP tests with bilateral microinfusions of saline $(n=17)$ or nadolol $(n=18)$ into the dHipp immediately after the first CPP test. Rats infused with either saline or nadolol demonstrated a CPP for the previously cocaine-paired chamber during the first test and during subsequent microinfusion-free tests overall (Figure $3 \mathrm{~b}$ ). ANOVA revealed a significant effect of chamber $\left(\mathrm{F}_{2,66}=\right.$ 85.54, $p<0.001)$, but no chamber-by-group interaction $\left(\mathrm{F}_{2,66}=0.24, p>0.05\right)$ or chamber-by-group-by-test interaction $\left(\mathrm{F}_{8264}=1.82, p>0.05\right)$. Post hoc analyses confirmed that during the first CPP test and subsequent microinfusion-free tests overall, both saline- and nadolol-treated rats spent significantly more time within the previously cocaine-paired chamber than in the saline-paired chamber $(p$ 's $<0.05)$. Thus, both saline- and nadolol-treated rats expressed a CPP following microinfusions, indicating that dHipp nadolol did not disrupt CPP memory reconsolidation.

We also determined dHipp nadolol microinfusions immediately after a CPP test would disrupt cocaine-induced reinstatement of the CPP. Following conditioning and daily CPP tests with microinfusions of nadolol or saline after the first test only (Figure 3b), rats were given a 14-day break followed by a final CPP extinction test, during which no CPP was expressed. The following day, rats were subjected to a cocaine-induced reinstatement test in the absence of saline or nadolol microinfusions. Rats previously infused with either saline or nadolol expressed cocaine-induced reinstatement of the CPP during this test (Figure 3c). ANOVA revealed an effect of chamber $\left(\mathrm{F}_{2,62}=31.62\right.$, $p<0.001)$ and a chamber-by-test interaction $\left(\mathrm{F}_{2,62}=4.73\right.$, $p<0.05)$, but no chamber-by-test-by-group interaction $\left(\mathrm{F}_{2,62}=1.30, p>0.05\right)$. Post hoc analyses confirmed that all rats spent an equivalent amount of time within the previously cocaine-paired and saline-paired chambers during the final CPP extinction test ( $p$ 's $>0.05)$. However, all rats spent significantly more time within the previously
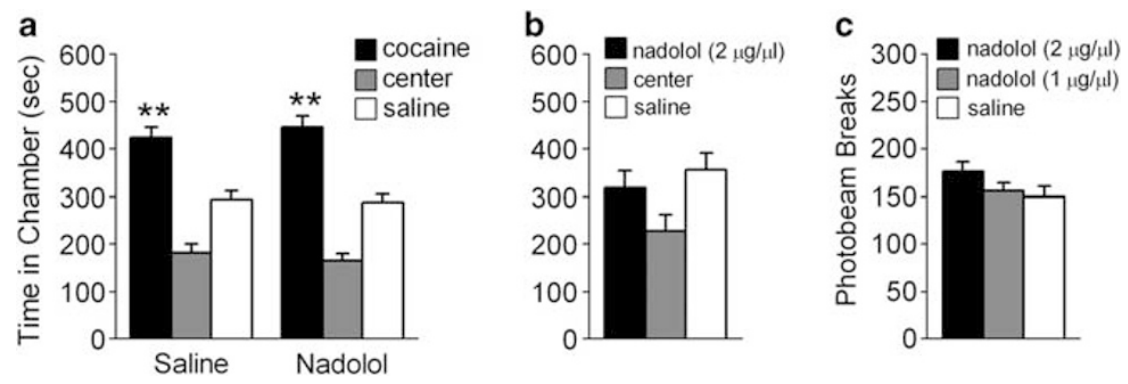

Figure 4 The effects of $\beta$-AR blockade on retrieval are not due to non-specific effects. (a) dHipp microinfusions of nadolol $(n=10)$ or saline $(n=14)$ did not prevent rats from expressing a CPP during a test $24 \mathrm{~h}$ later. (b) Following conditioning with dHipp microinfusions of nadolol or saline ( $n=12$ ), rats spent an equivalent amount of time within the nadolol-paired and saline-paired chambers. (c) Following dHipp microinfusions of a saline ( $n=17)$, a high dose of nadolol $(n=16)$, or a low dose of nadolol $(n=9)$, rats displayed equivalent locomotor activity during a CPP test as measured by photobeam breaks. *** $p<0.01$. 
cocaine-paired chamber than in the saline-paired chamber during the cocaine-induced reinstatement test $(p$ 's $<0.05)$. Thus, a dHipp nadolol microinfusion immediately after an initial CPP test did not prevent subsequent cocaine-induced reinstatement of the CPP.

\section{CPP Disruption Is Not Due to Non-Specific Effects of Nadolol Microinfusions}

The long-term effects of dHipp $\beta$-AR blockade on CPP expression could be non-specific to memory retrieval. Thus, we assessed the effects of dHipp $\beta$-AR blockade in the absence of a CPP test. Following conditioning, bilateral dHipp microinfusions of saline $(n=14)$ or nadolol $(n=10)$ were administered in the absence of testing, followed by a $\mathrm{CPP}$ test $24 \mathrm{~h}$ later. All rats expressed a CPP during this test (Figure 4a). ANOVA revealed a significant effect of chamber $\left(\mathrm{F}_{2,44}=58.43, p<0.001\right)$, but no chamber-by-group interaction $\left(\mathrm{F}_{2,44}=0.36, p>0.05\right)$. Post hoc analyses confirmed that all rats spent more time in the previously cocaine-paired chamber than in the saline-paired chamber during the CPP test $(p$ 's $<0.01)$. Thus, dHipp microinfusions of nadolol $24 \mathrm{~h}$ before a CPP test did not prevent rats from expressing a CPP.

We next determined whether dHipp microinfusions of nadolol alone were sufficient to induce an affective state, which could influence CPP expression. Rats were conditioned to associate one chamber, but not another, with dHipp microinfusions of nadolol $(n=12)$. During a subsequent drug-free CPP test, rats spent an equivalent amount of time within the conditioning chambers (Figure $4 \mathrm{~b}$ ). ANOVA revealed no effect of chamber during this test $\left(\mathrm{F}_{2,22}=2.28\right.$, $p>0.05$ ), indicating that rats spent an equivalent amount of time within all of the chambers. Thus, dHipp microinfusions of nadolol did not cause an affective state sufficient to induce a CPP or aversion. Moreover, nadolol had no effect on motor behavior. Rats infused with saline $(n=17), 1 \mu \mathrm{g} / \mu \mathrm{l}$ nadolol $(n=9)$, or $2 \mu \mathrm{g} / \mu \mathrm{l}$ nadolol $(n=16)$ before an initial $\mathrm{CPP}$ test had equivalent levels of photobeam breaks during that test $\left(\mathrm{F}_{2,39}=1.95, p>0.05\right.$; Figure $\left.4 \mathrm{c}\right)$.

Finally, we examined whether the effects of $\beta$-AR blockade on memory retrieval were specific to the dHipp. Following conditioning, rats were given daily CPP tests with bilateral microinfusions of nadolol $(n=7)$ into the cortex dorsal of dHipp before the first test. These rats were from the same cohort of rats used for experiments 1 and 2 (see Figures 1 and 2), which expressed a CPP across tests and expressed cocaine-induced reinstatement unless infused with dHipp nadolol before the first CPP test. Under identical conditions, rats infused with nadolol into cortex dorsal of dHipp demonstrated a CPP for the previously cocaine-paired chamber during the first test and during subsequent microinfusion-free tests overall (Supplementary Figure S2). Thus, the effects of dHipp nadolol are site specific, and not replicable by nadolol infusions into cortex dorsal of dHipp.

\section{DISCUSSION}

We investigated the necessity of dHipp $\beta$-AR activation in drug-associated memory retrieval. dHipp microinfusions of the $\beta$-AR antagonist nadolol blocked retrieval in a dose- and region-specific manner. This retrieval impairment was long lasting, provided protection against reinstatement, and occurred when nadolol was administered before the first CPP test or when administered before selective exposure to the previously cocaine-paired chamber. These effects were not present when nadolol was administered immediately after a CPP test, indicating that nadolol did not induce reconsolidation blockade. Thus, dHipp $\beta$-AR blockade persistently impaired memory retrieval without impairing memory reconsolidation.

Our finding that dHipp $\beta$-AR activation mediates CPP memory retrieval is consistent with studies demonstrating the necessity of the dHipp in contextual fear and drug-associated memory expression. dHipp inactivation or lesions disrupt context-dependent fear memory expression (Kim and Fanselow, 1992; Corcoran and Maren, 2001) and disrupt cocaine-induced CPP expression (Meyers et al, 2003, 2006). Mice lacking NE are unable to express contextinduced fear (Murchison et al, 2004) or drug-associated memories (Jasmin et al, 2006; Olson et al, 2006). However, pharmacological stimulation of dHipp $\beta$-ARs rescues contextual fear impairments in mice lacking $\mathrm{NE}$ (Murchison et al, 2004). Taken together, these data support our conclusion that drug-associated memory retrieval is dependent on activation of dHipp $\beta$-ARs.

Our results demonstrate that dHipp $\beta$-AR blockade after a CPP test does not disrupt memory reconsolidation or subsequent cocaine-induced reinstatement. Despite an attenuation of CPP expression following a post-test dHipp nadolol microinfusion (see Figure 3b, test 2), this attenuation was not significant between groups and was not present during subsequent CPP tests. Thus, the effect of dHipp $\beta$-AR blockade on reconsolidation may be transient. Consistent with this, inhibition of dHipp protein synthesis, which is downstream of $\beta-A R$ activation, following drug-associated cue exposure has no effect on memory reconsolidation in the self-administration model (Ramirez et al, 2009). Thus, stabilization of drug-associated memories during reconsolidation does not require dHipp $\beta$-AR dependent protein synthesis. Alternatively, destabilization of drug-associated memories may be dependent on dHipp $\beta$-AR signaling. Evidence supporting this hypothesis reveals that dHipp and basolateral amygdala (BLA) fire synchronously during memory reconsolidation (Narayanan et al, 2007) and disconnection of these structures prevents successful drug-associated memory reconsolidation (Wells et al, 2011). Moreover, synaptic input to BLA during reconsolidation destabilizes BLA synapses (Kim et al, 2010), allowing for subsequent stabilization processes for memory reconsolidation. Taken together, dHipp $\beta$-AR activation during retrieval is likely involved in memory destabilization, but not in memory re-stabilization.

Despite the evidence supporting dHipp $\beta$-AR involvement in retrieval, only a few recent studies have examined whether such mechanisms are required to successfully maintain future retrieval. We previously found that systemic injections or prelimbic medial prefrontal cortex (PL-mPFC) microinfusions of $\beta$-AR antagonists before retrieval of a cocaine-induced CPP memory induce longterm retrieval impairments. Furthermore, these effects were independent of reconsolidation blockade (Otis and Mueller 2011; Otis et al, 2013). Similarly, administration of a $\beta$-AR antagonist disrupts recall of visual memories and emotional words in humans (Kroes et al, 2010, 2012) and heroin- 
related words in human heroin addicts (Zhao et al, 2010). The effects of $\beta$-AR blockade on memory retrieval in humans are long lasting (Kroes et al, 2010, 2012), and may prevent memory reinstatement (Kroes et al, 2012). Data also reveal that inactivation of mineralocorticoid receptors before, but not after cue exposure induces short and longlasting impairments in contextual fear memory retrieval (Zhou et al, 2011). These investigations support our conclusions that neural processing in dHipp during retrieval is required to successfully maintain future retrieval and reinstatement.

An alternative explanation of our findings is that dHipp $\beta$-AR blockade facilitated extinction of the CPP. However, this interpretation is unlikely given that $\beta$-AR activation enhances, rather than impedes, memory formation (McGaugh, 2000). Accordingly, $\beta$-AR blockade impairs, rather than facilitates, extinction of several appetitive and aversive behaviors (Merlo and Izquierdo, 1967; Mueller et al, 2008; LaLumiere et al, 2010).

A 2-week break between CPP extinction tests did not result in spontaneous recovery of the CPP in any experiment. This was somewhat surprising, as spontaneous recovery has been observed in other Pavlovian conditioning procedures (Pavlov, 1927; Rescorla, 2004). However, recent experiments have revealed that spontaneous recovery of a CPP occurs following a 4-week but not 2-week break from testing (Ma et al., 2012). Thus, spontaneous recovery would be better studied if a longer break was introduced.

The persistent effects of dHipp $\beta$-AR blockade on drugassociated memory retrieval indicate that lasting changes in noradrenergic signaling may underlie our findings. Noradrenergic neurons, located in the locus coeruleus (LC), become active during the presentation of salient cues (Sara, 2009). Thus, the attribution of salience to cocaine-conditioned cues following learning suggests that these cues will induce noradrenergic activity. In support of this, the LC becomes active as stimulus-reinforcement contingencies are changed, and this neural response precedes alterations in behaviors (Aston-Jones et al, 1997; Sara and Segal, 1991). Moreover, direct stimulation of LC neurons elicits memory retrieval, an effect that is $\beta$-AR dependent (Devauges and Sara, 1991). Thus, salient cues induce LC activation, which initiates memory retrieval. Previously, we found that PLmPFC $\beta$-AR activation is required for retrieval, and blocking this activity induces retrieval impairments (Otis et al, 2013). Along with the present findings, this suggests that cocaine-conditioned cues induce retrieval by activating dHipp- and PL-mPFC-projecting LC neurons, leading to $\beta$ $\mathrm{AR}$ activation in these regions. Indeed, $\mathrm{NE}$ is released upon conditioned cue exposure (Cassens et al, 1980), which activates dHipp and PL-mPFC $\beta$-ARs (Otis et al., 2013; Pedarzani and Storm, 1993). This activation enhances neural excitability and excitatory synaptic activity within dHipp (Hopkins and Johnston, 1984; Pedarzani and Storm, 1993) and PL-mPFC (Ji et al, 2008; Otis et al, 2013). Thus, these structures become active following drug-associated cue exposure (Hearing et al, 2010; Hermann et al, 2006; Miller and Marshall, 2004; Neiswander et al, 2000), leading to memory retrieval. Inhibiting dHipp or PL-mPFC activation by blocking $\beta$-AR activity likely renders cocaine-conditioned cues less salient, preventing drug-associated memory retrieval. This effect could be due to reduced attention to these cues, disrupting the contingency between the context and cocaine. Thus, subsequent presentations of the chamber may no longer cause NE release, resulting in a persistent impairment in memory retrieval.

Presentation of drug-associated cues leads to cravings and relapse in human addicts. Preventing retrieval of these associative memories, through targeted dHipp $\beta$-AR blockade, would therefore limit relapse susceptibility. Clinical studies have demonstrated that treating human addicts with the non-selective NE inhibitor disulfiram (Carroll et al, 1998) or $\beta$-AR antagonist propranolol (Kampman et al, 2001; 2006) enhances treatment retention. The improved retention could be due to disruption of drug-associated memory retrieval or reconsolidation. We found that retrieval is only susceptible to disruption when dHipp $\beta$-AR blockade is coupled with drugassociated cue presentation. Thus, our findings suggest that coupling $\beta$-AR antagonists with exposure therapy, in which drug-associated cues are presented to addicts in the absence of the drug, would provide a powerful method for preventing cue-induced relapse to drug use.

\section{FUNDING AND DISCLOSURE}

The authors declare no conflict of interest.

\section{ACKNOWLEDGEMENTS}

This research was supported by DA027870 and a grant from the University of Wisconsin-Milwaukee Research Growth Initiative to DM. We thank Patrick Reilly for technical assistance.

\section{REFERENCES}

Aston-Jones G, Rajkowski J, Kubiak P (1997). Conditioned responses of monkey locus coeruleus neurons anticipate acquisition of discriminative behavior in a vigilance task. Neuroscience 80: 697-715.

Bernardi RE, Ryabinin AE, Berger SP, Lattal KM (2009). Postretrieval disruption of a cocaine conditioned place preference by systemic and intrabasolateral amygdala beta2- and alpha1adrenergic antagonists. Learn Mem 16: 777-789.

Carroll KM, Nich C, Ball SA, McCance E, Rounsavile BJ (1998). Treatment of cocaine and alcohol dependence with psychotherapy and disulfiram. Addiction 93: 713-727.

Cassens G, Roffman M, Kuruc A, Orsulak PJ, Schildkraut JJ (1980). Alterations in brain norepinephrine metabolism induced by environmental stimuli previously paired with inescapable shock. Science 209: 1138-1140.

Childress AR, McLellan AT, O’Brien CP (1986). Role of conditioning factors in the development of drug dependence. Psychiatr Clin North Am 9: 413-425.

Corcoran KA, Maren S (2001). Hippocampal inactivation disrupts contextual retrieval of fear memory after extinction. J Neurosci 21: $1720-1726$.

Debiec J, LeDoux JE, Nader K (2002). Cellular and systems reconsolidation in the hippocampus. Neuron 36: 527-538.

Devauges V, Sara SJ (1991). Memory retrieval enhancement by locus coeruleus stimulation: evidence for mediation by betareceptors. Behav Brain Res 43: 93-97.

Foltin RW, Haney M (2000). Conditioned effects of environmental stimuli paired with smoked cocaine in humans. Psychopharmacology (Berl) 149: 24-33. 
Fuchs RA, Evans KA, Ledford CC, Parker MP, Case JM, Mehta RH et al (2005). The role of the dorsomedial prefrontal cortex, basolateral amygdala, and dorsal hippocampus in contextual reinstatement of cocaine seeking in rats. Neuropsychopharmacology 30: 29.

Hearing MC, Schochet TL, See RE, McGinty JF (2010). Contextdriven cocaine-seeking in abstinent rats increases activityregulated gene expression in the basolateral amygdala and dorsal hippocampus differentially following short and long periods of abstinence. Neuroscience 170: 570-579.

Hermann D, Smolka MN, Wrase J, Klein S, Nikitopoulos J, Georgi A et al (2006). Blockade of cue-induced brain activation of abstinent alcoholics by a single administration of amisulpride as measured with fMRI. Alcohol Clin Exp Res 30: 1349-1354.

Hopkins WF, Johnston D (1984). Frequency-dependent noradrenergic modulation of long-term potentiation in the hippocampus. Science 226: 350-352.

Jasmin L, Narasaiah M, Tien D (2006). Noradrenaline is necessary for the hedonic properties of addictive drugs. Vascul Pharmacol 45: 243-250.

Ji XH, Cao XH, Zhang CL, Feng ZJ, Zhang XH, Ma L et al (2008). Pre- and postsynaptic beta-adrenergic activation enhances excitatory synaptic transmission in layer V/VI pyramidal neurons of the medial prefrontal cortex of rats. Cereb Cortex 18: $1506-1520$.

Kampman KM, Dackis C, Lynch KG, Pettinati H, Tirado C, Gariti P et al (2006). A double-blind, placebo-controlled trial of amantadine, propranolol, and their combination for the treatment of cocaine dependence in patients with severe cocaine withdrawal symptoms. Drug Alcohol Depend 85: 129-137.

Kampman KM, Volpicelli JR, Mulvaney F, Alterman AI, Cornish J, Gariti P et al (2001). Effectiveness of propranolol for cocaine dependence treatment may depend on cocaine withdrawal symptom severity. Drug Alcohol Depend 63: 69-78.

Kim J, Song B, Hong I, Lee J, Park S, Eom JY et al (2010). Reactivation of fear memory renders consolidated amygdala synapses labile. J Neurosci 30: 9631-9640.

Kim JJ, Fanselow MS (1992). Modality-specific retrograde amnesia of fear. Science 256: 675-677.

Kroes MC, Strange BA, Dolan RJ (2010). Beta-adrenergic blockade during memory retrieval in humans evokes a sustained reduction of declarative emotional memory enhancement. J Neurosci 30: 3959-3963.

Kroes MC, Tona KD, Muller N, Den Ouden HE, Van Wingen GA, Fernandez G (2012). Beta-Adrenergic Blockade Affects the Neural Network of Extinction Learning and Prevents the Return of Fear in Humans. Program No. 708.08. 2012 Neuroscience Meeting Planner. Society for Neuroscience: New Orleans, LA, 2012.

LaLumiere RT, Niehoff KE, Kalivas PW (2010). The infralimbic cortex regulates the consolidation of extinction after cocaine self-adminstration. Learn Mem 17: 168-175.

Lee JL, Everitt BJ, Thomas KL (2004). Independent cellular processes for hippocampal memory consolidation and reconsolidation. Science 304: 839-843.

Ma X, Zhang JJ, Yu LC (2012). Post-retrieval extinction training enhances or hinders the extinction of morphine-induced conditioned place preference in rats dependent on the retrieval-extinction interval. Psychopharmacology (Berl) 221: 19-26.

McGaugh JL (2000). Memory-a century of consolidation. Science 287: 248-251.

Merlo AB, Izquierdo I (1967). The effect of catecholamines on learning in rats. Med Pharmacol Exp Int J Exp Med 16: 343-349.

Meyers RA, Zavala AR, Neisewander JL (2003). Dorsal, but not ventral, hippocampal lesions disrupt cocaine place conditioning. Neuroreport 14: 2127-2131.
Meyers RA, Zavala AR, Speer CM, Neisewander JL (2006). Dorsal hippocampus inhibition disrupts acquisition and expression, but not consolidation, of cocaine conditioned place preference. Behav Neurosci 120: 401-412.

Miller CA, Marshall JF (2004). Altered prelimbic cortex output during cue-elicited drug seeking. J Neurosci 24: 6889-6897.

Mueller D, Porter JT, Quirk GJ (2008). Noradrenergic signaling in infralimbic cortex increases cell excitability and strengthens memory for fear extinction. J Neurosci 28: 369-375.

Mueller D, Stewart J (2000). Cocaine-induced conditioned place preference: reinstatement by priming injections of cocaine after extinction. Behav Brain Res 115: 39-47.

Murchison CF, Zhang XY, Zhang WP, Ouyang M, Lee A, Thomas SA (2004). A distinct role for norepinephrine in memory retrieval. Cell 117: 131-143.

Narayanan RT, Seidenbecher T, Sangha S, Stork O, Pape HC. (2007). Theta resynchronization during reconsolidation of remote contextual fear memory. Neuroreport 18: 1107-1111.

Neisewander JL, Baker DA, Fuchs RA, Tran-Nguyen LT, Palmer A, Marshall JF. (2000). Fos protein expression and cocaine-seeking behavior in rats after exposure to a cocaine self-administration environment. J Neurosci 20: 798-805.

Olson VG, Heusner CL, Bland RJ, During MJ, Weinshenker D, Palmiter RD (2006). Role of noradrenergic signaling by the nucleus tractus solitarius in mediating opiate reward. Science 311: 1017-1020.

Otis JM, Dashew KB, Mueller D (2013). Neurobiological dissociation of retrieval and reconsolidation of cocaine-associated memory. J Neurosci 33: 1271-1281.

Otis JM, Mueller D (2011). Inhibition of $\beta$-adrenergic receptors induces a persistent deficit in retrieval of a cocaine-associated memory providing protection against reinstatement. Neuropsychopharmacology 36: 1912-1920.

Pavlov IP (1927). Conditioned Reflexes: An Investigation of the Physiological Activity of the Cerebral Cortex. Oxford University Press: Oxford, England.

Pedarzani P, Storm JF (1993). PKA mediates the effects of monoamine transmitters on the $\mathrm{K}+$ current underlying the slow spike frequency adaptation in hippocampal neurons. Neuron 11: 1023-1035.

Ramirez DR, Bell GH, Lasseter HC, Xie X, Traina SA, Fuchs RA (2009). Dorsal hippocampal regulation of memory reconsolidation processes that facilitate drug context-induced cocaineseeking behavior in rats. Eur J Neurosci 30: 901-912.

Rescorla RA (2004). Spontaneous recovery. Learn Mem 11: 501-509. Sara SJ (2009). The locus coeruleus and noradrenergic modulation of cognition. Nat Rev Neurosci 10: 211-223.

Sara SJ, Segal M (1991). Plasticity of sensory responses of locus coeruleus neurons in the behaving rat: implications for cognition. Prog Brain Res 88: 571-585.

Wells AM, Lasseter HC, Xie X, Cowhey KE, Reittinger AM, Fuchs RA (2011). Interaction between the basolateral amygdala and dorsal hippocampus is critical for cocaine memory reconsolidation and subsequent drug context-induced cocaineseeking behavior in rats. Learn Mem 18: 693-702.

Wouda JA, Diergaarde L, Riga D, van Mourik Y, Schoffelmeer AN, De Vries TJ (2010). Disruption of long-term alcohol-related memory reconsolidation: role of $\beta$-adrenoceptors and NMDA receptors. Front Behav Neurosci 4: 1-7.

Zhao LY, Shi J, Zhang XL, Epstein DH, Zhang XY, Liu Y et al (2010). Stress enhances retrieval of drug-related memories in abstinent heroin addicts. Neuropsychopharmacology 35: 720-726.

Zhou M, Kindt M, Joels M, Krugers HJ (2011). Blocking mineralocorticoid receptors prior to retrieval reduces contextual fear memory in mice. PLOS ONE 6: e26220.

Supplementary Information accompanies the paper on the Neuropsychopharmacology website (http://www.nature.com/npp) 